\title{
O Novo rumo da formação docente em Bolívia Um movimento diferente?
}

\author{
JAQUELINE BITTENCOURT ${ }^{*}$ \\ Maria Luz Perez*
}

\begin{abstract}
RESUMO: O objetivo deste artigo é identificar sujeitos e descrever fatores no processo de mudança estrutural na educação boliviana, a partir da "Refundação do Estado", instituída mediante a promulgação da Constituição 2009. Nesse processo, houve um movimento de enfatizar o público em detrimento do privado, diferente de outros países na América Latina. Utilizamos a história e a organização da formação docente como fio condutor analítico da revolução cultural que se pretende instaurar na Bolívia, a partir do modelo sócio-produtivo instituído pela Lei da Educação de 2010.
\end{abstract}

Palavras-chave: Políticas de formação de professores. Educação no Estado Plurinacional da Bolívia. Relação entre o público e privado. Revolução cultural na educação boliviana.

\section{The New Course for Teacher Training in Bolivia A different movement?}

\begin{abstract}
The objective of this article is to identify subjects and describe factors in the process of structural change in Bolivian education, from the "Re-founding of the State", instituted through the promulgation of the 2009 Constitution. In this process, there was a movement to emphasize the "public" over the "private" which is dif-
\end{abstract}

* É Mestre e Doutora em Educação pela Universidade Federal do Rio Grande do Sul. Bolsista de Pós-doutorado (Capes) no Programa de Mestrado em Educação da Universidade do Oeste de Santa Catarina. Atualmente é professor à distância da Escola de Gestores da Universidade Federal do Rio Grande do Sul. Porto Alegre, RS- Brasil. E-mail: <jaqueline.bittencourt@ufrgs.br>.

** É Mestre em formação docente e inovação educativa e Doutora em Ciências e Humanidades. Atua como investigadora e docente de Programas de graduação e pós-graduação em diferentes instituições universitárias. Atualmente possui vínculo com a Universidade Católica Boliviana - Regional Cochabamba. Cochabamba, Bolívia. E-mail: <mardesic@ucbcba.edu.bo>. 
ferent to other countries in Latin America. We use the history and organization of teacher education as the analytical driver of the cultural revolution being established in Bolivia, based on the socio-productive model instituted by the Education Act of 2010.

Keywords: Teacher training policies. Education in the plurinational state of Bolivia. Relationship between public and private. Cultural revolution in Bolivian education.

\section{El Nuevo rumbo de la formación docente en Bolivia} ¿Un movimiento diferente?

RESUMEN: El objetivo de este artículo es identificar sujetos y describir factores en el proceso de cambio estructural en la educación boliviana a partir de la "Refundación del Estado", instituida mediante la promulgación de la Constitución de 2009. En ese proceso, hubo un movimiento para enfatizar lo público en detrimento de lo privado, diferentemente de otros países en Latinoamérica. Utilizamos la historia y la organización de la formación docente como hilo conductor analítico de la revolución cultural que se pretende instaurar en Bolivia, a partir del modelo social y productivo instituido por la Ley de la Educación de 2010.

Palabras clave: Políticas de formación de profesores. Educación en el Estado Plurinacional de Bolivia. Relación entre público y privado. Revolución cultural en la educación boliviana.

Le nouveau parcours de formation des enseignants en Bolivie Un mouvement différent?

RÉSUMÉ: L'objectif de cet article est d'identifier les sujets et de décrire les facteurs du changement structurel dans l'éducation bolivienne, à partir de la "Refondatin de l'État", instituée par la promulgation de la Constitution de 2009. Dans ce processus, il y a eu un mouvement différent des autres pays d'Amérique latine. Nous utilisons l'histoire et l'organisation de la formation des enseignants comme le fil conducteur analytique de la révolution culturelle qui 
prétend d'établir en Bolivie, sur la base du modèle socio-productif institué par la loi de 2010 sur l'éducation.

Mots-clés: Politiques de formation des professeurs. Éducation dans l'État plurinational de Bolivie. Relation entre le public et le privé. Révolution culturelle dans l'éducation bolivienne.

\section{Introdução}

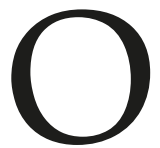

artigo tenta refletir sobre os processos de transformação estrutural em curso na Bolívia, mudanças que aconteceram a partir da promulgação da Constituição Política do Estado (2009) e da implementação da Lei da Educação no 070 Avelino Siñani - Elizardo Pérez (2010), ${ }^{1}$ mediante o modelo sócio-comunitário produtivo no sistema educacional e, particularmente, na formação de professores.

Inicialmente apresentamos uma contextualização da normativa atual para posteriormente realizar a abordagem do que constitui o modelo sócio-comunitário produtivo no sistema plurinacional de formação docente. Finalmente, colocamos algumas considerações finais, na tentativa de responder a pergunta: O Estado Plurinacional da Bolívia está num movimento diferente, dentro da tendência histórica de privatização na América Latina?

\section{Contexto histórico normativo}

Uma das tendências mais evidentes nas sociedades democráticas ocidentais, nas últimas décadas, tem sido a de atender os direitos sociais, sem que se deixe de atender os interesses do mercado e do capital. Esta tensão se dá na decisão de qual é o papel do Estado.

Sabemos que discutir a questão do papel do Estado é, como afirma Graciarena (1984, p. 39,) "aproximar-se à Torre de Babel. Ainda mais, dentro do marco singular e contraditório como é na América Latina". Esta região tem uma história onde os paradigmas se apresentam de forma híbrida, especialmente no período após a redemocratização nos anos 1990 e 2000, ou seja, com o fim das ditaduras militares, neste período houve um crescimento das ideias neoliberais, ao passo em que governos progressistas ascendiam ao poder, dando um tom "abigarrado" 2 à silhueta da América do Sul.

Se na América Latina temos visto este processo implementado de forma muito variada, particularmente na Bolívia houve um movimento de ampliar a ingerência do Estado, de forma acentuada, principalmente, na educação. Este processo se inicia com 
a aprovação da Constituição, também conhecida como o marco da "Refundação do Estado", em fevereiro de 2009. Isso alavancou um processo de mudança estrutural sem precedentes na história.

O novo ordenamento teve como eixo principal a promoção do abandono da concepção de república e a adopção do conceito de Estado Plurinacional. Esta mudança, longe de ser apenas a denominação do país, trouxe um profundo movimento na base da sociedade bolíviana, em termos culturais, econômicos e sociais (SARZURI-LIMA, 2011; LASERNA, 2010).

A reestruturação é uma resposta histórica aos conflitos desde o período colonial e chega apoiada numa série de ideias nacionalistas - populares e da luta contra a dominação de

[...] vários grupos instituídos, que gerem e reproduzem estruturas, mas que também as modificam e, a princípio, as criam, não pela fixação direta das suas vontades em objetividades sociais, é sim o resultado da sobre determinação de todas as práticas sociais e políticas na que, no entanto, um grupo (que pode se plural) impõe suas direções, seus valores e sua força física e cultural (TAPIA, 2009, p. 9) (Tradução nossa).

É possível reconhecer dentro do Movimento ao Socialismo (MAS) - partido político que está no poder - três grupos de sujeitos que compartilham ideias de uma novo status quo: os indigenistas, inicialmente representados pelo ex-chanceler David Choquehuanca, cuja tarefa era dar visibilidade aos originários nacional e internacional, num discurso que entra em vigência de forma aberta. Ele quem trabalha com a ideia da necessidade da "revolução democrática e cultural", dentro de um processo de descolonização. $\mathrm{O}$ segundo grupo é o que está formado pelos intelectuais orgânicos do socialismo boliviano, e seu representante mais importante é o atual vice-presidente, Álvaro García Linera, cujo ideário se sustenta na expansão da intervenção do Estado em todos os aspectos da vida do país. Para Laserna (2009, p.39):

Este grupo se nutre de militantes da velha esquerda estatista que vai dos ideólogos marxistas, até os tecnocratas dispostos a reeditar a industrialização por substituição das importações que era sustentada pela Comissão Econômica para América Latina e o Caribe (Cepal) nos anos de 1950 e 1960. A transição ao socialismo consiste, para este grupo, em manter o estatismo nacionalista na economia.

O terceiro grupo é representado pelo presidente Evo Morales Ayma cuja raiz está nos "movimentos sociais"; este grupo tem o papel protagonista desde a sua ascensão ao poder, até a sustentação das propostas de mudança. Trata-se das organizações populares de sindicatos, organizações de vizinhos e outros, que são o alicerce da nova estrutura social do Estado Plurinacional da Bolívia.

Deste modo, é possível reconhece as ideias dos sujeitos nas diretrizes que orientam a construção do novo Estado e, como consequência, a elaboração da nova lei da Educação denominada Avelino Siñani e Elizardo Pérez, promulgada em dezembro de 2010. 
Assim, se coloca em prática a transição curricular, que avança lentamente e será apresentada mais adiante.

O texto constitucional define o ingresso de Bolívia na era do Estado Plurinacional, comunitário e com autonomias, para tanto, o Art. $1^{\circ}$ sinaliza que:

Bolívia constitui-se num Estado Unitário Social de Direito Plurinacional Comunitário, livre, independente, soberano, democrático, intercultural, descentralizado e com autonomias. Bolívia funda-se na pluralidade e o pluralismo político, econômico, jurídico, cultural e linguístico, dentro do processo integrador do país (CPE, 2009).

Daí deriva a necessidade de vincular este modelo de Estado com o tipo de educação estabelecido na norma constitucional.

Ao mesmo tempo, o Art. 77, parágrafo II da CPE (2009) estabelece:

O Estado e a sociedade têm ingerência plena sobre o sistema educativo, que compreende a educação regular, alternativa e especial, assim, como a educação superior de formação profissional. O sistema educativo desenvolverá os processos baseado em critérios de harmonia e coordenação.

Destaca-se nesta afirmação que, por um lado, estão muito claras as bases fundamentais do tipo de Estado que se queria construir, e, por outro lado, a necessidade de que este assuma a ingerência plena do Sistema Educacional Nacional, concretizando todos os princípios que fundam a nova sociedade que se deseja e se requer.

Para conseguir este propósito, está sendo implementado o Plano Nacional de Desenvolvimento Econômico e Social (PND), já oferecido na época pré-eleitoral. Nele se projeta o desenvolvimento do país na direção da construção de uma "Bolívia digna, soberana, produtiva e para viver bem". O PND está baseado em quatro áreas estratégicas nacionais:

Estratégia econômica: Bolívia Produtiva, baseada nos setores que constituem a matriz produtiva e dos que apoiam o seu funcionamento.

Estratégia sócio-comunitária: Bolívia Digna, inclui os setores distribuidores de fatores e meios de produção, assim como serviços sociais.

Estratégia de relacionamento internacional: Bolívia Soberana, compreende as relaciones econômicas, políticas e culturais e incluí setores vinculado ao comercio e intercâmbio de bens, serviços e capitais.

Estratégia do poder social: Bolívia Democrática, compreende os setores que promovem o poder social nos territórios.

Outro documento que complementa a visão do PND é a Agenda Patriótica (AP) 2025, elaborada em 2013. No que corresponde a colocar à educação como meio de consolidar o Estado Plurinacional, este documento mostra a visão do país, até 2025, com melhores condições de vida para os bolivianos nas áreas da saúde, educação, desporto, integração, mantendo a soberania alimentar e o acesso soberano ao Oceano Pacífico velho sonho da nação. 
A AP tem uma concepção estratégica do país e sua virtude é retomar o planejamento como medida técnica, focando nos problemas como a erradicação da pobreza extrema, a universalização dos serviços básicos, a saúde, a educação e desporto, além de soberania financeira, produtiva e alimentar, entre os pontos altos, vislumbrando o Bicentenário do país. (AP, 2013).

As estratégias para a recuperação da dignidade e soberania estão sendo viabilizadas através de diferentes projetos e programas dirigidos à mudança e à melhoria dos serviços de educação, saúde, saneamento básico, seguridade social, moradias e infraestrutura pública etc.

Como aponta Mardesich (2014, p. 13), paralelamente ao processo de transformação que está vivendo o Estado e se coloca nos documentos já descritos, o Sistema Educativo Plurinacional também está passando por uma profunda transformação organizacional, estreitamente alinhado com o arcabouço legal.

A Lei Educativa no 070 propõe mudanças significativas, instituind o o enfoque educativo sócio-comunitário produtivo. O propósito é constituir uma nova cultura de Estado, onde pretende-se desenvolver quatro revoluções, desde o âmbito educativo. ${ }^{3}$

Revolução do conhecimento, o que significa mudar a educação bancária que os sistemas anteriores geraram, através de uma descolonização do conhecimento, mas, ao mesmo tempo, recuperar a riqueza da cultura local para criar uma sociedade com sua própria identidade. Esta revolução exige mudar a prática do professor centrado até agora em questões pedagógicas, circunscritas à sala de aula, pouco ligadas à realidade social. A revolução do conhecimento passa por uma prática pedagógica renovada, inovadora, reflexiva, crítica, mediadora entre conhecimento e realidade.

A revolução tecnológica-produtiva, referente à articulação entre teoria e prática, concretizada no conhecimento científico, assumindo que os problemas de produção estão ligados ao contexto local, municipal e nacional e que podem ser alterados e alterar o próprio sistema produtivo no Estado. Para isso, é necessário influenciar - desde a sala de aula - dando utilidade e a aplicabilidade ao conhecimento.

Revolução social-democrática, que procura reduzir os níveis de exclusão, discriminação, entre outros, mas não apenas como a própria tarefa do professor, mas também gerand o corresponsabilidade dos pais, escola e comunidade. Este tipo de revolução deve permitir a toda a sociedade assumir a responsabilidade na transformação do Estado, instituindo espaços de participação.

A revolução ética significa transformar a consciência das pessoas. A partir do respeito à Mãe Terra, superando a visão antropocêntrica, ampliando para uma consciência ecológica coletiva, que permita uma convivência harmoniosa entre o homem e a natureza. A concepção biocêntrica é assumida como uma política pública inclusiva e integral porque promove valores sócio- comunitários ao longo do processo pedagógico. 
É importante reconhecer que os processos experimentados como país eram necessários, principalmente devido à preocupação de garantir o direito fundamental à educação, e ao legado histórico da educação boliviana, que, como afirmam Bittencourt e Chávez (2007), foi construído a partir de uma "dicotomia entre o rural e o urbano", fato que representava uma divisão racial e não apenas uma divisão geográfica ou regional. $\mathrm{O}$ que significa que a revolução proposta é uma unificação do sistema educacional, pensada no povo boliviano, respeitando sua diversidade cultural, linguística e de costumes, próprios das diferentes nações aglutinadas no território nacional. Tudo isso expresso no primeiro capítulo da Lei 070 de 2010:

\section{Artigo 1}

1. Todos têm o direito de receber educação em todos os níveis de forma universal, produtiva, gratuita, integral e intercultural, sem discriminação.

2. A educação é uma função suprema e a primeira responsabilidade financeira do Estado, que tem a obrigação inabalável de sustentá-la, garanti-la e gerenciá-la.

3. O Estado e a sociedade têm ingerência total sobre o sistema educacional, que inclui educação regular, alternativa e especial e ensino superior de formação profissional. O sistema educacional desenvolve seus processos com base em critérios de harmonia e coordenação.

4. O sistema educacional é composto por instituições de educação pública, instituições educacionais privadas e instituições de convênio.

5. A educação é unitária, pública, universal, democrática, participativa, comunitária, descolonizadora e de qualidade.

6. A educação é intracultural, intercultural e multilíngue em todo o sistema educacional.

7. O sistema educacional baseia-se em uma educação aberta, humanística, científica, técnica e tecnológica, produtiva, territorial, teórica e prática, libertadora e revolucionária, crítica e favorável.

8. A educação é obrigatória até o final do ensino médio (bachillerado).

9. A educação pública é gratuita em todos os níveis até o superior.

Chamamos a atenção para o item 2, que está diretamente relacionado ao compromisso que a legislação assume quando afirma que esta é a primeira responsabilidade financeira do Estado. Este é, sem dúvida, um avanço muito importante na garantia de recursos para que essa revolução se efetive.

Também é interessante notar que o item 8 enfatiza a obrigação, sem fazer diferença de gênero ou idade, assegurando, por exemplo, que as meninas bolivianas tenham as mesmas oportunidades que historicamente não tiveram. 


\section{Formação docente no sistema plurinacional}

Outra parte da revolução, iniciada com a Lei Avelino Siñani - Elizardo Pérez (2010, artigo 32), está focada na formação docente. Ela diz que a formação será única, pública, gratuita, continuada e diversificada - unificando o sistema rural e urbano. O sistema é único em termos de hierarquia profissional e qualidade pedagógica e científica. Pública e gratuita, porque o Estado assume toda a responsabilidade na formação dos professores. Diversificado, porque responde às características geográficas econômicas, produtivas e socioculturais. Todo subsistema de formação de professores é eminentemente intracultural, intercultural e multilíngue, tendo em conta a diversidade linguística, cultural e geográfica do país, com o objetivo de capacitar novos professores no âmbito da educação produtiva e comunitária, com base no conhecimento e conhecimento das nações indígenas e originárias e as características dos diferentes setores populares e sociais.

Da mesma forma, garante uma sólida formação nas ciências da educação, social, humanística, natural, exata, técnica, artística e disciplinas nas quais se especializa.

Os institutos normais superiores e outros centros públicos de formação de professores foram transformados em Escola Normal Superior de Formação Docente, formando o Subsistema Nacional de Formação Docente, sob a gestão do Ministério da Educação com o papel de capacitar professores para os sistemas de educação regular, alternativa e especial. De acordo com a seguinte nomenclatura:

\section{Quadro n 1 : Especialidades na Formação Docente}

\begin{tabular}{|c|c|c|}
\hline \multicolumn{2}{|c|}{ Nível } & Especialidades \\
\hline \multicolumn{3}{|c|}{ Licenciatura em Educação Inicial na família comunitária } \\
\hline \multirow{5}{*}{$\begin{array}{l}\text { Licenciatura em Educação } \\
\text { Primária comunitária } \\
\text { vocacional }^{*}\end{array}$} & $\begin{array}{l}\text { Primária básica } \\
\text { vocacional }\end{array}$ & \\
\hline & \multirow{4}{*}{$\begin{array}{l}\text { Primária avançada } \\
\text { vocacional }\end{array}$} & Ciências Exatas \\
\hline & & Ciências Naturais \\
\hline & & Ciências Sociais \\
\hline & & Linguajem e Literatura \\
\hline
\end{tabular}




\section{Nível}

Especialidades

Matemática

Ciências Naturais (Física, Química, Biologia e Geografia)

Linguajem e Literatura

Educação em línguas

Filosofia, Psicologia e Cosmovisão

Licenciatura em Educação Secundária Comunitária produtiva** $^{* *}$

\section{Ciências Sociais}

(Menção em: História, Sociologia, Antropologia, Educação cidadania)

Educação artística

Menção em:

Educação musical, dança e teatro

Artes plásticas e visuais

Educação física y disciplinas desportivas

Licenciatura em Educação Alternativa e especial Educação Popular comunitária e Educação para a diversidade

Educação especial

Fonte: Compendio de documentos curriculares (2008).

* A partir da Estrutura Curricular na Primária da Comunidade Vocacional se espera que as crianças, desde uma idade precoce, identifiquem suas inclinações e, por outro lado, em função do atual Modelo Educacional, o Estado pretende identificar as vocações produtivas do contexto; por isso, a insistência na formação do técnico-humanista e na realização de projetos sócio-produtivos que visam responder às demandas do contexto (Currículo Base, 2012).

* A abordagem produtiva tem duas modalidades: a produção na educação é um recurso pedagógico para pôr em prática os saberes e o conhecimento; nesse sentido, todo processo educacional é produtivo. A produção é um meio para desenvolver qualidades e capacidades articuladas às políticas públicas, como a soberania alimentar, ligadas à autonomia com que produzimos e à transformação da matriz produtiva, para desenvolver e dotar de outros meios de vida, assim como o desenvolvimento de potencialidades e vocações produtivas territoriais (Currículo Base, 2012, p. 30.).

O Ministério da Educação concede o título de Maestro(Professor) no grau de Licenciatura com reconhecimento no "Escalafón Nacional". 4 Este é um registro que reconhece aqueles formados nas escolas superiores de professores. O tempo de estudo é de cinco anos para todos os níveis, áreas e modalidades do Sistema Educacional Plurinacional, ficando garantida sua inserção laboral nas diferentes regiões do país. ${ }^{5}$

Os docentes e diretores de Escola Superior de Formação de Professores são profissionais com título de professor e grau acadêmico igual ou superior ao nível do grau que lecionam. 
Ao mesmo tempo cria-se a Universidade Pedagógica de Pós-graduação, de caráter público, que faz parte do Sistema Educativo Plurinacional, sob a gestão do Ministério da Educação, que orienta e promove a pesquisa científica em educação e a formação permanente de professores do Estado Plurinacional.

Mardesich e outros (2012, p.26), destacam os novos fatores da Lei de Educação:

» A formação docente é responsabilidade do Estado.

» O processo de formação docente inclui cinco anos, o que permite o grau acadêmico de licenciatura.

» A formação de pós-graduação está sob a responsabilidade da Universidade Pedagógica, dependente do Ministério da Educação, com o objetivo de qualificar mediante cursos de especialização, mestrado e doutorado para professores com grau de licenciatura, assim como promover a pesquisa na educação.

» A educação trilíngue, que requer professores a capacidade de se comunicar em espanhol, um idioma original e uma língua estrangeira.

» É enfatizada a necessidade de capacitar professores com a capacidade de incorporar a gestão de novas tecnologias de informação e comunicação na tarefa educacional.

» Neste momento, o Desenho Curricular de Base (DCB) para a formação docente está sendo implementado nas escolas superiores de formação de professores.

» Os professores formados nos planos anteriores ao novo desenho, devem acessar o Programa de Formação Complementar (Profocom), com o objetivo de atingir o grau de licenciatura. ${ }^{6}$

\section{A estrutura de formação docente}

A estrutura de formação docente dentro do Sistema Educacional Plurinacional inclui: a) Formação na graduação/licenciatura b) Formação continuada e c) Formação de pós-graduação, que está sob a responsabilidade do Ministério da Educação, através do Subsistema de Formação Superior e Formação Profissional através da Direção Geral de Formação de Professores. As políticas, diretrizes e estratégias operacionais oficiais para a formação na graduação ou inicial, continuada e pós-graduação são responsabilidade dessas instâncias governamentais.

No Gráfico 1, observamos a dinâmica que orienta o ideário da formação docente. Cad um dos componentes tem estabelecido suas responsabilidades no processo formativo da seguinte forma: 


\section{Gráfico 1: Sistema Plurinacional da Formação Docente}

\section{SISTEMA PLURINACIONAL DE FORMACIÓN DE MAESTROS}

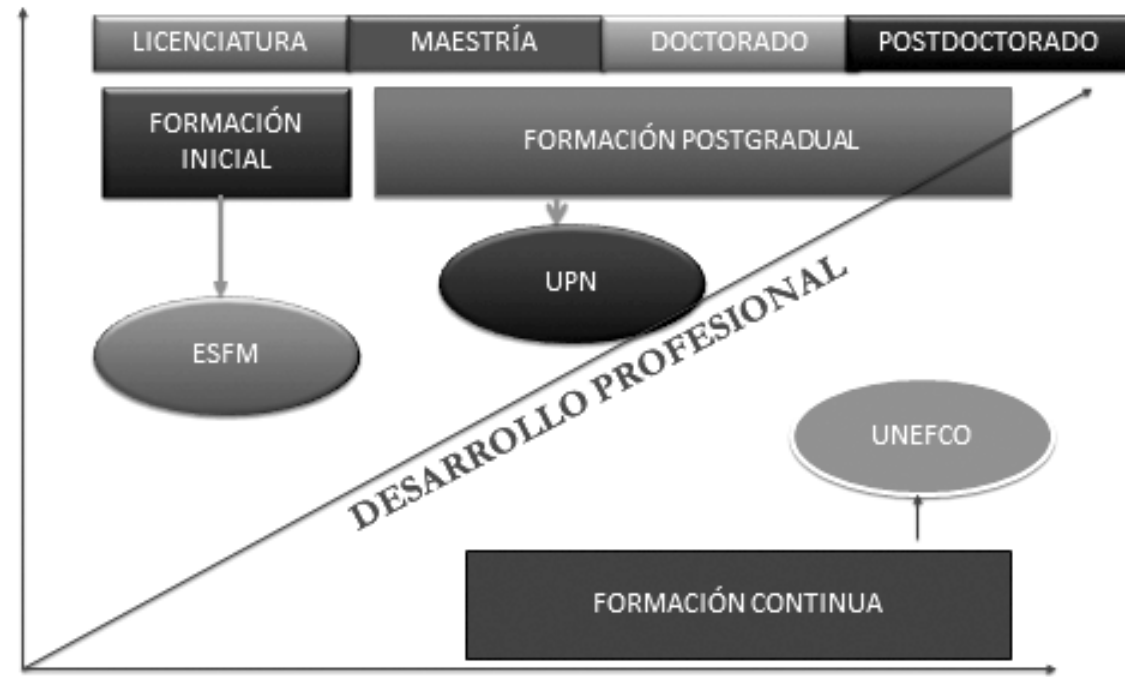

Fonte: Desenho Curricular Base da Educação Boliviana (2012)

\section{a) Formação inicial graduação/licenciatura}

As Escolas Superiores de Formação de Professores (ESFM) são as instituições que, em forma exclusiva, têm sob sua responsabilidade a oferta e desenvolvimento de programas acadêmicos de graduação de professores, de acordo com o Art. 36, da Lei Avelino Siñani-Elizardo Pérez.

Essas instituições tem caráter desconcentrado e dependem da Direção Geral de Formação de Professores (DGFM) e sua estrutura está formada por diretores, coordenadores, administrativos e pessoal de apoio acadêmico e estudantes.

As Unidades Acadêmicas (UA) são entidades desconcentradas dependentes das ESFM cuja máxima autoridade é o coordenador. Por exemplo: no Departamento ${ }^{7}$ de Cochabamba existe a Escola Superior de Formação de Professores "Simón Rodríguez", cujas unidades acadêmicas se encontram nas Províncias de Sacaba, Quillacollo y Chapare.

Há perspectivas de transformar às ESFM a partir do seguinte objetivo:

Desenvolver como centros de excelência acadêmica, os processos que garantam a formação integral de professores para o Sistema Educativo Plurinacional, comprometidos com a democracia, as transformações sociais, a inclusão plena de todos os bolivianos e bolivianas com alto nível acadêmico nas especialidades da prática educativa comunitária e a geração de inovações no âmbito pedagógico e a construção 
de conhecimentos, com o compromisso social e a vocação de serviço, integrando à comunidade e descolonizando a educação e, assim, Viver Bem em comunidade (DCB 2012, p. 25) (tradução nossa).

\section{b) Formação continuada}

A Unidade Especializada de Formação Continuada (Unefco) é a instância que desenha, organiza, executa e avalia os processos de formação continuada para docentes, técnicos, administrativos do Sistema Educativo Plurinacional atendendo o Art. 40 da Lei da Educação.

A Unefco é uma unidade desconcentrada do Ministério de Educação que atua em todo o país, tem dependência direta da pasta através do Vice-ministério de Educação Superior de Formação Professional, através da Direção General de Formação de Professores.

Este ente formou a Rede Plurinacional da Centros de Formação Continuada, em que se desenvolvem projetos sistemáticos variados e suportam a formação continuada em todo o país. Com pertinência e relevância cultural e linguística, seu principal objetivo é:

Desenvolver processos de formação continuada para docentes em exercício, pessoal técnico-administrativo do Sistema Educativo Plurinacional, orientados à sua atualização e capacitação para melhorar a qualidade da gestão, os processos e resultados do ambiente educativo, fortalecendo as capacidades inovadoras dos educadores, seu compromisso social e a vocação de serviço, incorporando estratégias de formação na prática e da formação para a prática que melhorem a qualidade educativa (DCB 2012 p. 26) (tradução nossa).

c) Pós-graduação

Para esta etapa se criou a Universidade Pedagógica "Mariscal Sucre" que é a instância responsável pela implementação da pós-graduação em educação, sua ênfase está na pesquisa educacional e na geração de recursos humanos altamente qualificados para realizar as tarefas educativas, do planejamento e de gestão do sistema como estabelece o Art. 39 da Lei 070.

Sendo uma Universidade de regime especial, a Universidade Pedagógica, tem dependência direta do Ministério da Educação, mediante o Vice-ministério da Educação Superior de Formação Profissional e da Direção Geral de Formação de Professores.

Seu principal objetivo é:

Desenvolver processos de formação na pós-graduação de alto nível acadêmico, com ênfase na investigação educativa e da prática educativa comunitária, orientada para à qualificação nas especialidades, na recuperação e produção de conhecimentos e 
a pertinente resolução de problemas da realidade no âmbito educativo, consolidando enfoques e práticas educativas que respondam à realidade e ás necessidades do Estado Plurinacional". Para tanto, os programas de pós-graduação ofertadas pela Universidade Pedagógica têm alcance nacional e se constituem numa oportunidade de aprofundamento na formação profissional nas diversas especialidades, na pesquisa, planejamento e gestão educativa para professores e professoras e dos técnicos administrativos do Sistema Educativo Plurinacional (DCB 2011, p. 26) (tradução nossa).

\section{Programa de formação complementar/continuada (Profocom)}

No ano de 2013 se iniciou a transformação educativa nas salas de aulas no primeiro de primária (ensino fundamental) e o primeiro de secundaria (ensino médio) de todo o território nacional. Foram muitas as expectativas, críticas e incertezas, principalmente, pelo fato de não ter se implementado com todas as condições institucionais e curriculares instituídas na Lei. Uma dessas condições era formação docente; esta tarefa foi assumida pelo Programa de Formação Complementária (Profocom), com o objetivo de que os educadores se apropriem do modelo pedagógico. No entanto, não houve tempo suficiente para que isso fosse realizado, no início.

Em 2014, ano em que a transformação chegava a todos os níveis e anos da escolaridade, continuava a desinformação, mesmo com a maioria dos professores dentro do Profocom e com a difusão de diversos materiais de apoio bibliográfico orientador disponíveis na plataforma do Ministério de Educação. Constatava-se problemas de interpretação dos conteúdos nas diversas instâncias onde ainda não há clareza sobre o novo processo pedagógico. Os educadores declaram sentir o peso de realizar um trabalho num ambiente de incerteza, ceticismo e desconfiança no fazer cotidiano, optando em alguns casos por repetir o modelo antigo.

Por outro lado, o Profocom, para professores em exercício com diploma de técnico superior, tem uma duração de quatro semestres, tempo em que são desenvolvidas 20 unidades de formação de 2.400 horas, com ênfase no trabalho na sala de aula e na comunidade. O processo finaliza com a elaboração de um produto grupal de sistematização de experiências numa área do modelo socio-comunitário produtivo alcançada com a soma de produtos individuais, reunidos num texto didático, ou uma produção audiovisual curta.

Uma vez que a fase anterior é concluída, os professores podem continuar seu processo de formação, acessando programa de mestrado, que dura cinco semestres. Nele se desenvolvem 24 unidades de formação, em 3.264 horas acadêmicas, onde a ênfase é colocada na pesquisa e na inovação educacional. O processo termina com a elaboração de um produto individual, que consiste na realização de uma investigação-ação na 
perspectiva da abordagem sócio-crítica, que constitua um aporte à melhoria da implementação do modelo socio-comunitário produtivo.

Este momento de transformação educativa deveria ser assumido pelos educadores como uma oportunidade para reconstituir a experiência acumulada nos anos anteriores, para juntar esforços e conseguir uma compreensão adequada do desenvolvimento curricular, fortalecer a comunidade educacional e, ao mesmo tempo, compartilhar com os outros atores educacionais o escopo da verdadeira transformação da realidade, fortalecendo o modelo socio-comunitário produtivo.

\section{Considerações finais}

Observa-se que, no marco nacional geral, os consensos obtidos entre os diversos setores sociais trouxeram soluções e complicações na aplicação prática desta revolução em curso. Existem contradições na construção de políticas que respondam às necessidades sócio-econômicas latentes, provocando um descontentamento no processo vivido, colocando em questionamento a própria democracia representativa, especialmente diante do acesso ao poder de setores sociais, antigamente esquecidos e marginalizados, que estão grandemente representados no atual governo, fato que revela a divisão racial histórica no país.

Na educação, a série de mudanças não se desenvolveu sem conflitos. Ano após ano, se retomam as discussões em cima das dificuldades na implementação da Lei Educativa. Há uma fricção constante entre o governo e os professores, por um lado, e os grupos dos próprios professores que apoiam ou criticam o atual sistema, por outro. Ainda existem conflitos latentes próprios da educação boliviana, qual seja, a dicotomia na divisão entre rural e urbano que ainda persiste agora nos sindicatos profissionais, como se fosse uma ferida que não cicatriza.

Certamente, no que se refere à formação docente, o Profocom se destaca por ter mobilizado milhares de docentes no país, e é peça importante na concretização da nova prática pedagógica, que articula o social, o comunitário e o produtivo e requer uma atitude otimista e inovadora, provocando uma nova forma de entender a realidade. No entanto, a revolução pela educação se percebe de forma tímida, inclusive porque, como toda ação educativa, leva algumas gerações para poder avaliar os resultados concretos. Se percebe, sim, um novo arranjo institucional e legal que rege o sistema e aponta para uma garantia ao acesso e permanência, mas ainda de forma precária e sem qualidade.

Nesse cenário se encontra a educação boliviana e a formação docente em particular. Por isso, cabe pontuar e acompanhar para onde este modelo educativo sócio-comunitário produtivo vai, ao passo em que tomamos conhecimento de algumas das suas características. 
Finalmente, concordamos com os imperativos levantados por Magdalena Cajías de la Vega (2011), ao se referir à transformação em curso, assinalando que é necessária a participação ativa dos professores nos processos decisórios da educação no nível local e nacional; é necessária a discussão da formação docente com professores, alunos, pais, instituições formadoras e outros segmentos da sociedade; é necessário reestabelecer vínculos e mecanismos entre os diferentes sistemas educacionais para chegar no denominador comum sobre a qualidade do conjunto da educação boliviana, como meio de diminuir as diferenças sociais; é importante discutir os currículos das ESFM nos aspectos do uso de línguas e o trato das culturas e povos originários, entre outros (CAJÍAS DE LA VEGA, 2011).

Teríamos muito para aportar nessa discussão. No entanto, acreditamos que já é um avanço relevante poder descrever o rumo da formação docente no Estado Plurinacional da Bolívia.

Acreditamos que respondemos parcialmente ao questionamento sobre se o processo boliviano é diferenciado e se vai numa tendência histórica contrária à privatização na América Latina. A resposta é que todo este processo demonstra uma profunda diferença; obviamente, ainda fica um espectro analítico de outros fatores, para verificar se os conteúdos das propostas pedagógicas terão o mesmo caráter das outras diretrizes. No entanto, elas estão respondendo algumas das questões históricas de divisão racial social e econômica na sociedade boliviana. Outros resultados, somente a história nos responderá.

Recebido em 15/11/2017 e aprovado em 05/01/2017

\section{Notas}

1 Homenagem a dois professores ícones na história de Educação Boliviana.

2 Este termo descreve a imagem que se adverte nas cidades de América latina, composto de muitos elementos diversos, sem ordem nem conexão estética, de cores,etc.

3 Extraído da exposição do vice-ministro da Educação Regular, José Quiroz, na cerimônia de inauguração do Workshop de Ajuste e Revisão do Currículo Base Inicial e Primária, realizado em Sacaba (Cochabamba), em 2 de outubro de 2013, bem como uma entrevista pós-exposição no mesmo dia.

4 É um registro que normatiza e regulamenta o plano de carreira docente, seguindo a trajetória profissional dos professores, tanto nos anos de serviço como na sua remuneração.

5 Na Bolívia, quem se forma como professor está habilitado para ingressar automaticamente no sistema público e o Estado garante sua estabilidade funcional. Isto não acontece em outras profissões, já que para se inserir no sistema laboral é necessário passar por processos de seleção que atestem suas qualificações para exercer sua carreira. Por este motivo se denomina Profissão Livre. 
6 Os docentes formandos nos planos anteriores obtinham grau de Nível Técnico Superior e deveriam complementar sua formação numa universidade para obter o grau de licenciatura.

7 O Estado boliviano é dividido em nove departamentos e cada um dele possui suas províncias.

\section{Referências}

BITTENCOURT, Jaqueline Marcela Villafuerte; CHÁVEZ, María Isabel Torrico. A Dicotomia da Organização Educacional Bolíviana: Uma Análise Histórica. Porto Alegre: Anais. 13º Encontro da Associação Sul-Rio-Grandense de Pesquisadores em História da Educação - Asphe. 2007.

ESTADO PLURINACIONAL DE BOLÍVIA. Constitución Política del Estado Plurinacional de Bolivia. Gaceta Oficial de Bolívia: La Paz, 2009.

Plan de Desarrollo Económico y Social Estado Plurinacional de Bolivia en el marco del desarrollo integral para vivir bien 2016 - 2020. Disponível em: http://www.planificacion.gob.bo/pdes/. Acesso em: Ago. 2017.

Ley de la Educación Avelino Siñani - Elizardo Pérez. № 070, Gaceta Oficial de Bolívia. La Paz, 2010.

Currículo Base del Sistema Educativo Plurinacional. Currículo Subsistema de Educação

Regular. Serie currículo. Documento de trabalho. 2012.

Currículo de formación de maestras y maestros del Sistema Educativo Plurinacional, Ministerio de Educación, s/e, La Paz, 2011.

Diseño Curricular Base de la Educación Boliviana: Avances y tensiones. Campaña Boliviana por el Derecho a la Educación. Ed. Agencia Española de Cooperación Internacional para el Desarrollo, La Paz, 2012.

Ministerio de Educación. Periódico mensual Comunidad - Abril, 51, 2017.

Agenda Patriótica, La Paz, 30 de noviembre de 2013.

CAJÍAS DE LA VEGA, Magdalena. Continuidades y Rupturas: el proceso histórico de la formación docente rural y urbana en Bolivia. Programa de Investigación Estratégica en Bolivia. La Paz, 2011.

GARCIA, Ana María e VELASCO, Oscar. La formación Docente en Bolívia “Nuevos retos de la profesión docente". III Seminario Internacional de la Red Europea y Latinoamericana de la profesión docente. Disponible en http://www.ub.edu/relfido/docs/NUEVOS_RETOS_DE_LA_PROFESION_ DOCENTE.pdf. Acesso em: jul. 2017.

GRACIARENA. Jorge. El Estado latinoamericano en perspectiva. Figuras, crisis, prospectiva. Disponible en: http://publicaciones.sociales.uba.ar/index.php/entramadosy perspectivas/article/ view/535/473. Acesso em: set. 2017.

LASERNA. Roberto. Mire, la democracia Boliviana, en los hechos... Centro de Estudios de la Realidad Económica y Social, Fundación Milenio. Disponible en: Latin American Research Review, Special Issue ( 2010 by the Latin American Studies Association. Acesso em: Ago. 2017. 
LUNA, Dario. Transición a una educación revolucionaria, democrática y cultural, Ley 070 Ministerio de Educación. Marzo 12, 2013. Disponible en: http://educacionBolívia.com/ley-070-una-revoluciondemocratica-y-cultural/. Acesso em: jun. 2017.

MARDESICH, María Luz. Una mirada al Currículo Base del Sistema Educativo Plurinacional. Colección Perspectiva Pedagógica. Editorial Verbo Divino, 2014.

MARDESICH, María Luz; GARCÍA, Ana María e VELASCO, Oscar. Un desafío para la educación: Formar docentes. La formación docente en Bolivia. Editorial Académica Española, Saarbrücken, Alemania, 2012.

TAPIA, Luis. La coyuntura de la autonomía relativa del estado. Editorial Muela del Diablo, La Paz, 2009.

SARZURI-LIMA. Marcelo. Descolonizar la educación: Elementos para superar el conservadorismo y funcionalismo cultural. Integra Educativa. Vol. IV / №3, 2011. 